\title{
ESTIMASI BIOMASSA PERMUKAAN DAN STOK KARBON PADA TEGAKAN POHON Avicennia marina DAN Rhizophora mucronata DI PERAIRAN PESISIR OEBELO KABUPATEN KUPANG
}

\author{
Glucklich Manafe $^{1)^{*}}$, Michael Riwu Kaho ${ }^{1,2)}$, Fonny Risamasu ${ }^{1,3)}$ \\ ${ }^{1)}$ Program Magister Ilmu Lingkungan,Universitas Nusa Cendana, Kupang \\ Jl. Adisucipto Penfui Kupang \\ ${ }^{2)}$ Fakultas Peternakan,Universitas Nusa Cendana, Kupang Jl. Adisucipto Penfui Kupang \\ ${ }^{33}$ Fakultas Perikanan,Universitas Nusa Cendana, Kupang Jl. Adisucipto Penfui Kupang \\ "Email : lmanafe@gmail.com
}

\begin{abstract}
Mangrove forest has an important function for living thing especially in the ocean and coastal area. Besides as feeding and nursery ground, mangrove forest is also has a function as carbon sinker. The utilizing of mangrove forest as a corbon sinker is one of ways to reduce $\mathrm{CO}_{2}$ in atmosphere. Mangrove forest in Oebelo village has a capability to utilize as carbon sinker. The aim of this research was to estimate above ground biomass and carbon reserve from two mangrove species Avicennia marina and Rhizopora mucronata in coastal area of Oebelo Village. In this research data was collected from diameter breast high and litter from forest floor. Alometric was used to estimate the above ground biomass. After data collected, analysis would continue with t test to know the different between these two species. The result showed A. marina and $R$. mucronata were different, the highest biomass, carbon reserve and $\mathrm{CO}_{2}$ sequestration were

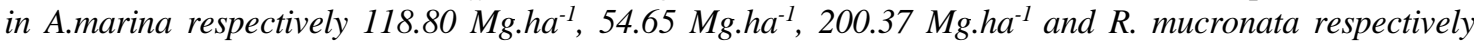
$28.90 \mathrm{Mg} \cdot \mathrm{ha}^{-1}$, $13.30 \mathrm{Mg} \cdot \mathrm{ha}^{-1}$, $48.75 \mathrm{Mg} \cdot \mathrm{ha}^{-1}$. The result for litter biomass and carbon reserve showed there was no different between these tow species.
\end{abstract}

Keywords: Avicennia marina; Rhizopora mucronata; biomass; carbon stock

\begin{abstract}
Abstrak
Hutan bakau memiliki fungsi penting untuk makhluk hidup terutama di laut dan wilayah pesisir. Selain sebagai tempat mencari makan dan tempat tinggal bagi makhluk hidup hutan bakau juga memiliki fungsi sebagai penyimpan karbon. Memanfaatkan hutan bakau sebagai penyimpan karbon salah satunya adalah untuk mengurangi $\mathrm{CO}_{2}$ di atmosfer. Hutan bakau di Desa Oebelo memiliki kemampuan sebagai penyimpan karbon. Tujuan dari penelitian ini adalah untuk memperkirakan biomassa di atas tanah dan cadangan karbon dari dua spesies bakau Avicennia marina dan Rhizopora mucronatadi daerah pesisir Oebelo. Data penelitian yang dikumpulkan dari diameter bakau setinggi data dan sampah diatas permukaan tanah. Alometrik digunakan untuk memperkirakan biomassa di atas tanah.Analisis dilakukan dengan menggunakan uji t untuk perbedaan simpanan karbon dari kedua jenis bakau tersebut. Hasil penelitian menunjukkan biomassa, cadangan karbon, dan serapan $\mathrm{CO}_{2}$ dari Avicennia marina dan Rhizopora mucronata berbeda, masing masing 118.80 Mg.ha-1, 54.65 Mg.ha ${ }^{-1}$, 200.37 Mg.ha ${ }^{-1}$ spesies Avicennia marina dan 28.90 Mg.ha ${ }^{-1}$, 13.30 Mg.ha-1, 48.75 Mg.ha ${ }^{-1}$ spesies Rhizopora mucronata. Hasil untuk biomassa sampah dan cadangan karbon menunjukkan tidak ada perbedaan antara dua spesies ini.
\end{abstract}

Kata kunci: Avicennia marina;Rhizopora mucronata; biomassa;simpanan karbon 


\section{Pendahuluan}

Perubahan iklim akibat pemanasan global semakin menjadi perhatian yang serius bagi kelangsungan kehidupan manusia di bumi saat ini. Pemanasan global adalah kenaikan rata-rata suhu permukaan bumi dan laut dibandingkan dengan abad-abad sebelumnya. Pemanasan global di sebabkan oleh naiknya kosentrasi gas rumah kaca di atmosfer.

Berbagai tindakan dan upaya mitigsi dapat dilakukan dalam mengantisipasi pemanasan global, salah satunya melalui upaya mitigasi penyerapan karbon oleh hutan mangrove. Hutan mangrove mampu menyimpan karbon 4 kali lebih banyak dari hutan tropis (Daniel $d k k$., 2011). Selain itu hutan mangrove memiliki tingkat penyerapan lima kali lebih cepat terhadap unsur karbon di udara jika dibandingkan dengan hutan di daratan (Imiliyana $d k k, 2012$ ). Tiap tahun hutan mangrove dapat menyerap 42 juta ton karbon di udara atau setara dengan emisi gas karbon dari 25 juta mobil (Ardianto, 2011).Hutan mangrove secara global mampu menghasilkan produksi primer sebanyak $218 \pm 72 \mathrm{Tg} \mathrm{C} \mathrm{yr}^{-1}$ (Bouillon et al, 2008) dimana akar menghasilkan sekitar 38\%, serasah dan kayu berkisar $31 \%$ dari total produksi primer yang dihasilkan dan deforestasi mangrove menyebabkan emisi sebesar 0,02- 0,12 Pg karbon per tahun yang setara dengan sekitar $10 \%$ emisi dari deforestasi secara global, walaupun luasnya hanya $0,7 \%$ dari seluruh kawasan hutan tropis.

Hutan mangrove yang berada di desa Oebelo mempunyai potensi yang cukup besar dalam menyimpan karbon.Hutan yang didominasi oleh Avicennia marina dan Rhizopora mucronataini memiliki luas \pm 1082 ha dengan panjang garis pantai $\pm 2.5 \mathrm{~km}$. namun pada beberapa tempat hutan ini sudah mengalami kerusakan karena adanya pembukaan lahan untuk dijadikan daerah tambak garam abu.Selain itu, beberapa kerusakan yang terjadi juga diakibatkan oleh aktifitas penebangan oleh masyarakat sekitar untuk dijadikan sebagai kayu bakar.

Penyerapan karbon oleh mangrove berhubungan dengan proses "sekuestrasi" yaitu penyerapan karbon dari atmosfer dan disimpan dalam organ tumbuhan, serasa dan bahan organic tanah dan diikat dalam bentuk biomassa pohon (Hairiah dan Rahayu., 2007) oleh karena itu hutan mangrove yang ada di desa Oebelo dapat dimanfaatkan dalam upaya mitigasi penyerapan karbon, hal ini karena Avicennia marinayang merupakan spesies dominan pada hutan ini mempunyai kemampuan yang baik dalam menyerap dan menyimpan karbon.Avicennia marina mempunyai kemampuan $75 \%$ lebih cepat dalam menyerap karbon dibandingkan dengan Rhizophoramucronata(Kathiresan dkk., 2013).

Salah satu metode yang dapat digunakan untukmengestimasi biomassa ialah metode alometrik (Komiyama $d k k$, 2007). Estimasi dilakukan dengan cara mengukur diameter batang pohon setinggi dada (Diameter at Breast Height, DBH) yang terdapat pada plot penelitian. Kemudian DBH digunakan sebagai variabel bebas dari persamaan alometrik yang menghubungkan biomassa sebagai variabel terikat dan DBH sebagai variabel bebas.

Tujuan dari penelitian ini ialah untuk mengetahui perbandingan biomassa dan stok karbon dari dua tegakan yang mendominasi hutan mangrove yang ada di Oebelo. Dalam penelitian ini data yang akan di ambil ialah diameter setinggi dada dan nekromassa tidak berkayu.

\section{Metodologi}

Penelitian ini dilaksanakan pada bulan Maret-April 2014. Titik pengambilan sampel berada pada dua lokasi yaitu yang pertama berada pada posisi $10^{\circ} 05^{\prime} 26.1$ ” LS; $123^{\circ} 44^{\prime} 50.2^{\prime \prime ~ B T ~}$ yang di dominasi oleh tegakan Avicennia marina dan kedua berada pada posisi $10^{\circ} 5$, 35.5" LS; $123^{0} 44^{\prime} 51.0^{\prime \prime}$ BT dimana tegakan Rhizopora mucronata mendominasi. Pembuatan plot yang digunakan untuk mengukur nilai biomassa vegetasi hutan mangrove di desa Oebelo mengikuti prosedur yang telah dibuat oleh Hairiah dan Rahayu (2007). 


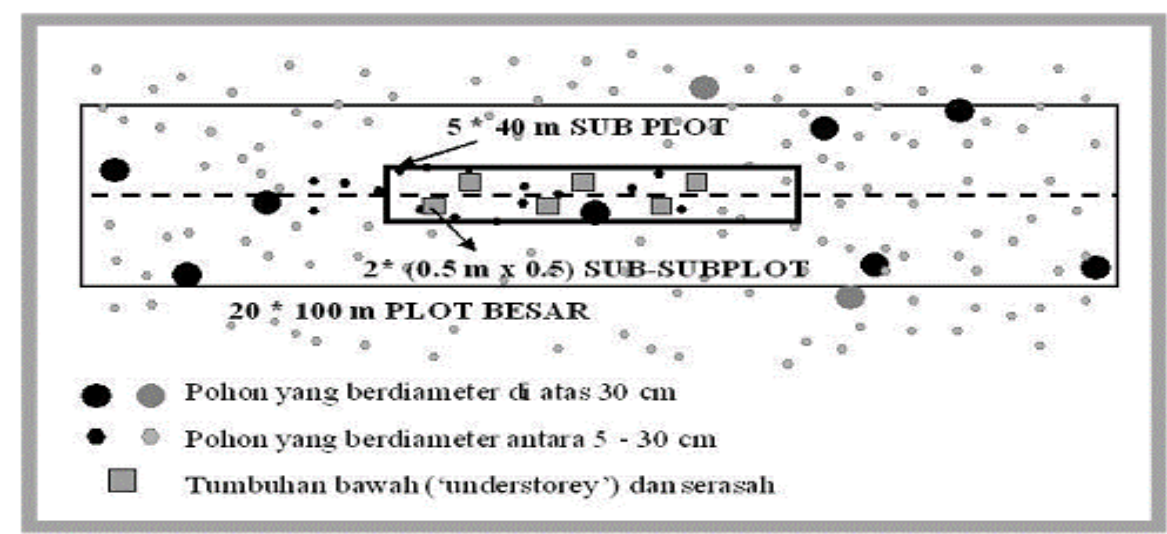

Gambar 1. Bentuk plot dan ukuran plot untuk tiap kelas diameter

Sub plot dibagi menjadi 2 bagian, dengan memasang tali di bagian tengah sehingga ada subsub plot, masing-masing berukuran $2.5 \mathrm{~m} \mathrm{x} 40$ m.Mencatat setiap nama pohon, dan menguukur diameter batang setinggi dada $(\mathrm{dbh}=$ diameter $a t$ breast height $=1.3 \mathrm{~m}$ dari permukaan tanah)semua pohon yang masuk dalam sub-sub plot sebelah kiri dan kanan. Pengukuran DBH hanya dilakukan pada pohon berdiameter $>5 \mathrm{~cm}$. Pengukuran tinggi DBH menggunakan tongkat kayu ukuran panjang $1.3 \mathrm{~m}$ yang dletakkan tegak lurus permukaan tanah di dekat pohon yang akan diukur kemudian diberi tanda goresan pada batang pohon. Bila permukaan tanah di lapangan dan bentuk pohon tidak rata, maka penentuan titik pengukuran DBH pohon dapat dilihat pada Gambar 2. Melilitkan pita pengukur pada batang pohon, dengan posisi pita sejajar untuk semua arah, sehingga data yang diperoleh adalah lingkar/lilit batang bukan diameter. Data keliling batang ini kemudian akan di ubah menjadi diameter dengan persamaan 1 (Simon, 2007):

$$
D=K / \pi
$$

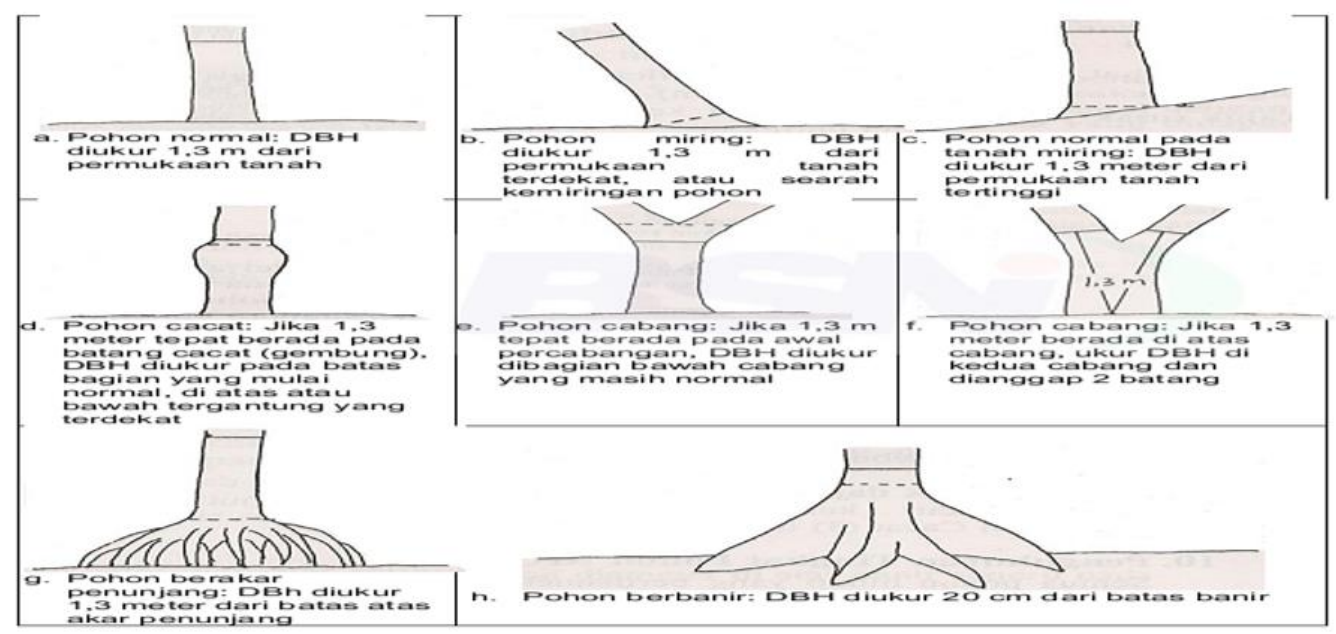

Gambar 2. Skematis cara menentukan ketinggian pengukuran dbh batang pohon yang tidak beraturan bentuknya 
Pengukuran biomassa dilakukan dengan cara "non destructive", yaitu menggunakan persamaan alometrik yang telah dikembangkan oleh peneliti lain sebelumnya dengan cara destructive. Persamaan alometrik yang digunakan untuk Avicennia marina adalah menurut Dharmawan dan Siregar (2008) dengan persamaan alometriknya adalah Yatas $=0.1848(D)^{2.3524}$ dan untuk Rhizophora mucronata menurut Dharmawan (2010) Yatas $=0.1466(\mathrm{DBH})^{2.3136}$. Menurut MacDicken 1997, penentuan biomassa dapat disusun minimal menggunakan 30 pohon contoh terpilih yang terbaik, sehingga dalam penelitian ini akan dipilih sebanyak 15 contoh tegakan pohon Avicennia marina dan Rhizophora mucronata sehingga di dapat total 30 pohon contoh.

Pengukuran nekromasa tidak berkayu dilakukan dengan meletakkan kuadran kayu berukuran 0,5 $\mathrm{m}$ x 0,5 $\mathrm{m}$ di tempatkan di dalam sub plot kemudian diambil semua sisa-sisa bagian tanaman mati, daun-daun dan ranting-ranting gugur yang terdapat dalam tiap-tiap subplot, di masukkan ke dalam kantong kertas dan diberi label sesuai dengan kode subplot. Semua sampel yang didapat dikeringkan di bawah sinar matahari, bila sudah kering sampel digoyang-goyangkan agar tanah yang menempel pada sampel terpisah. Mengambil sub-contoh sampel sebanyak $100 \mathrm{~g}$ untuk dikeringkan dalam oven pada suhu $80^{\circ} \mathrm{C}$ sampai beratnya konstan. Bila sampel yang didapat hanya sedikit ( $<100 \mathrm{~g}$ ), maka ditimbang semuanya dan dijadikan sebagai sub contoh.Estimasi BK seresah kasar per kuadran melaluiperhitungan sebagai berikut(Persamaan 2):

Total $B K=\frac{B K \text { sub contoh }}{\text { Berat basah sub contoh }} x$ total $B B$

Keterangan

$\mathrm{BK}=$ berat kering

$\mathrm{BB}=$ berat basah .

Konsentrasi karbon dalam bahan organik biasanya sekitar 46 \% (Hairiah dan Rahayu, 2007; Brown, 1997, Barnes $d k k$, 1998), oleh karena itu estimasi jumlah karbon tersimpan per komponen dapat dihitung dengan mengalikan total berat biomassanya dengan konsentrasi karbon. Untuk menghintung stok karbon dari pendugaan biomassa tegakan maupun nekromassa tidak berkayu menggunakan perhitungan (Brown, 1997; Dharmawan, 2010; Hairiah $d k k$, 2011; SNI 7724:201; Imiliyana $d k k, 2012$, Agustin $d k k$, 2012):

$$
C=\text { berat biomassa total } x 0.46
$$

Untuk mengetahui besarnya serapan $\mathrm{CO} 2$ oleh tanaman mangrove menggunakan Persamaan 3 (Dharmawan, 2010; Imiliyana $d k k$, 2012; Agustin $d k k, 2012)$ :

$$
\mathrm{CO}_{2}=\frac{\mathrm{MrCO}_{2}}{\mathrm{ArC}} x \text { kandungan } \mathrm{C}
$$

\section{Keterangan \\ $\mathrm{MrCO}_{2}=$ Berat molekul senyawa (44) \\ $\operatorname{Ar} \mathrm{C}=$ Berat molekul relatif atom C (12)}

Setelah perhitungan biomassa, stok karbon dan serapan $\mathrm{CO}_{2}$ di dapat maka akan dilanjutkan dengan uji $\mathrm{t}$ untuk mengetahui perbedaan antara Avicennia marina dan Rhizophora mucronata.

\section{Hasil dan Pembahasan}

\subsection{Biomassa Tegakan, Stok karbon dan Serapan $\mathrm{CO}_{2}$}

Berdasarkanpersamaan alometrik yang telah dikembang oleh Darmawan dan Siregar (2008) dan Dharmawan (2010) maka di dapat biomassa tegakan sebagai berikut.

Tabel 1. Biomassa, stok dan serapan karbon dari A. marina dan $R$. mucronata $(\mathrm{Mg} / \mathrm{ha})$

\begin{tabular}{cccc}
\hline Jenis & Biomassa & $\begin{array}{c}\text { Stok } \\
\text { Karbon }\end{array}$ & $\mathrm{CO}_{2}$ \\
\hline $\begin{array}{c}\text { Avicenia } \\
\text { marina }\end{array}$ & $118.80^{\mathrm{a}}$ & $54.65^{\mathrm{a}}$ & $200.37^{\mathrm{a}}$ \\
$\begin{array}{c}\text { Rhizopora } \\
\text { mucronata } \\
\text { Total }\end{array}$ & $28.90^{\mathrm{b}}$ & $13.30^{\mathrm{b}}$ & $48.75^{\mathrm{b}}$ \\
\hline
\end{tabular}


Dari tabel di atas dapat lihat bahwa kandungan biomassa terbesar ada pada jenis $A$. marina.Hasil uji t menunjukkan adanya perbedaan antara tegakan A.marina dan $R$. mucronata baik itu pada biomassa, stok karbon dan serapan $\mathrm{CO}_{2}$.

Perbedaan ini disebabkan karena diameter pohon (dbh) A.marina jauh lebih besar dari $R$. mucronata,pada plot pengukuran $A$. marinaditemukan individu yang memilki diameter lebih dari $30 \mathrm{~cm}$. Keberadaan pohon berdiameter $>30 \mathrm{~cm}$ pada suatu tipe lahan, memberikan sumbangan yang cukup berarti terhadap total cadangan karbon pada biomassa pohon. Semakin banyak pohon penyusun suatu lahan berdiameter > $30 \mathrm{~cm}$ maka cadangan karbon pada lahan tersebut makin tinggi (Hanafi dan Bernardianto, 2012).Besarnya biomassa ditentukan oleh diameter, tinggi tanaman, kerapatan kayu dan kesuburan tanah (Kusmana et al, 1992).

Peningkatan kelas diameter pohon berkolerasi positif terhadap peningkatan jumlah biomassa. Umur tegakan mangrove akan berbanding lurus dengan kandungan biomassanya. Gaol et al (2009) dan Hatia \& Tochiaki et al (1968) mengatakan bahwa gambaran umur populasi sering dinyatakan dalam diameter, sehingga semakin bertambah umur tanaman, maka semakin besar kandungan biomassa di atas tanah dimana menurut penelitian sebelumnya yang dilakukan oleh Prasty (2011) yang dikutip oleh Imiliyana (2012) yang meneliti kandungan biomassa pada beberapa kelas umur tanaman mangrove Rhizophora apiculata di Kabupaten Kubu Raya, Kalimantan Barat menemukan bahwa kandungan biomassa mangrove akan mengalami peningkatan seiring dengan bertambahnya usia tanaman. Hal ini disebabkan karena diameter pohon mengalami pertumbuhan melalui pembelahan sel yang berlangsung secara terus menerus dan akan semakin lambat pada umur tertentu (Pebriandi $d k k, 2013)$.

Siregar et al (1995) menyatakan $98.7 \%$ biomassa dipengaruhi oleh diameter setinggi dada (dbh) dan jumlah pohon yang digunakan akan turut berpengaruh karena penentuan jumlah biomassa dalam penelitian ini menggunakan persamaan alometrik yang sangat di pengaruhi oleh jumlah dan diameter pohon (Mejupan, 2001). Hasil penelitian Dharmawan dan Siregar (2008) pada $A$. marina dengan jumlah pohon contoh yang digunakansebanyak 47 pohon contoh menghasilkan biomassa sebesar 364.9 tonha $^{-}$ ${ }^{1}$ sedangakan dalam penelitian ini menggunakan 15 pohon contoh diperoleh biomassa sebesar 118.80 $\mathrm{Mg} \mathrm{ha}{ }^{-1}$ dan untuk $R$. mucronatamenurut hasil penelitian Dharmawan (2010) yang menggunakan pohon contoh sebanyak 35 pohon contoh menghasilkan biomassa sebesar 77.2 ton ha ${ }^{-1}$ sedangkan dalam penelitian ini pohon contoh yang digunakan sebanyak 15 dengan biomassa sebesar $28.90 \mathrm{Mg} \mathrm{ha}^{-1}$.

Stok karbon tertinggi juga terdapat pada tegakan A.marina yaitu54.65 Mg.ha ${ }^{-1}$,sedangkan R. mucronata sebesar $13.30 \mathrm{Mg} \cdot \mathrm{ha}^{-1}$. Perbedaan cadangan karbon yang tersimpan disebabkan adanya perbedaan besaran diameter di antara tegakan dimana semakin besar diameter pohon penyusun suatu lahan, maka berat biomassa pohon pada lahan tersebut akan semakin besar pula. Berat biomassa yang besar akan mempengaruhi besarnya cadangan karbon pada suatu lahan (Hanafi dan Bernardianto, 2012). Individu tegakan yang memiliki diameter $>30 \mathrm{~cm}$ merupakan tempat cadangan karbon terbesar pada suatu lahan. Hairiah dan Rahayu (2007) juga menyatakan bahwa potensi stok karbon dapat dilihat dari biomassa tegakan yang ada.Besarnya stok karbon tiap bagian pohon dipengaruhi oleh biomassa. Oleh karena itu, setiap peningkatan terhadap biomassa akan diikuti oleh peningkatan stok karbon. Hal ini menunjukkan besarnya biomassa berpengaruh terhadap stok karbon.

Batang merupakan kayu dimana 40 - 46\% kayu tersusun oleh selulosa. Selulosa merupakan molekul gula linear berantai panjang yang tersusun oleh karbon, sehingga semakin tinggi selulosa maka kandungan karbon akan semakin tinggi. Faktor tersebut menyebabkan kelas diameter yang lebih besar akan memiliki kandungan karbon yang lebih tinggi pula. Makin besar diameter pohon 
diduga memiliki potensi selulosa dan zat penyusun kayu lainnya akan lebih besar.

Karbon merupakan suatu unsur yang diserap dari atmosfer melalui proses fotosintesis dan disimpan dalam bentuk biomassa. Tingkat penyerapan karbon di hutan dipengaruhi oleh berbagai faktor, antaralain iklim, topografi, karakteristik lahan, umur dan kerapatan vegetasi, komposisi jenis serta kualitas tempat tumbuh.Tempat penyimpanan utama karbon adalah terdapat dalam biomassanya (termasuk bagian atas yang meliputi batang, cabang, ranting, daun, bunga, dan buah serta bagian bawah yang meliputi akar), bahan organik mati, tanah dan yang tersimpan dalam produk kayu yang nantinya dapat diemisikan untuk produk jangka panjang.

Serapan $\mathrm{CO}_{2}$ tertinggi juga terdapat pada

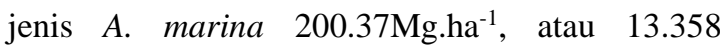
$\mathrm{Mg} /$ pohon, sedangkan $R$. mucronata $48.75 \mathrm{Mg} \cdot \mathrm{ha}^{-1}$ atau $3.250 \mathrm{Mg} /$ pohon.Besarnya serapan $\mathrm{CO}_{2}$ ini juga berbanding lurus dengan diameter suatu pohon, makin besar diameter maka $\mathrm{CO}_{2}$ yang diserapnya semakin besar (Darmawan dan Siregar, 2008), hal ini di kuatkan dengan pendapat Gaol et al (2009) yang mengatakan bahwa meningkatnya diameter disebabkan karena penyimpanan biomassa hasil konversi $\mathrm{CO}_{2}$ yang semakin bertambah besar seiring dengan semakin banyaknya $\mathrm{CO}_{2}$ yang diserap pohon.

Secara umum hutan dengan net growth (terutama pohon-pohon yang sedang berada dalam fase pertumbuhan) mampu menyerap lebih banyak $\mathrm{CO}_{2}$, sedangkan hutan dewasa dengan pertumbuhan yang kecil menahan dan menyimpan persediaan karbon tetapi tidak dapat menyerap $\mathrm{CO}_{2}$ ekstra (Pebriandi $d k k, 2013$ ).

\subsection{Biomassa Nekromassa Tidak Berkayu}

Biomassa pada lantai hutan mangrove menjadi salah satu indikator jumlah pasokan bahan organik yang menjadi salah satu rantai makanan dalam ekosistem perairan mangrove dan pasokan utama biomassa lantai hutan yang berasal dari sersah vegtasi yang jatuh. Besarnnya potensi biomassa nekromassa tidak berkayu dapat dilihat pada Tabel 2.

Tabel 2. Biomassa nekromassa tidak berkayu ( $\mathrm{Mg} / \mathrm{ha})$

\begin{tabular}{ccc}
\hline Jenis & Biomassa & Stok Karbon \\
\hline $\begin{array}{c}\text { Avecennia } \\
\text { marina } \\
\text { Rhizopora } \\
\text { mucronata } \\
\text { Total }\end{array}$ & $0.30^{\mathrm{a}}$ & $0.14^{\mathrm{a}}$ \\
\hline
\end{tabular}

Dari hasil uji t di dapati bahwa tidak ada perbedaan biomassa, stok karbon dan $\mathrm{CO} 2$ nekromassa diantara ke dua jenis mangrove tersebut. Tidak adanya perbedaan di antara kedua jenis ini di duga karena posisi kedua stasiun yang berada di pantai dan muara sungai, di mana pasang surut mempengaruhi produksi biomassa lantai hutan di kedua stasiun. Pasang surut menyebabkan serasah yang berada pada lantai hutan akan terbawa menuju tempat lain. Pada stasiun dua muara sungai akan mengalami peningkatan volumenya ketika terjadi pasang sehingga sehingga serasah yang ada akan terbawa menuju tempat lain, hal yang sama juga terjadi pada stasiun I ketika terjadi pasang ataupun surut serasah akan terbawa oleh arus laut. Hal ini sesuai dengan pernyataan Snedaker and Lahmann et al, 1988, Allen et al 2000, Krauss et al 2005, hutan mangrove secara umum menghasilkan sedikit biomassa serasah atau bahkan cenderung tidak menghasilkan biomassa serasah sama sekali akibat terbawa aliran air, sehingga kontribusinya terhadap total karbon sangat kecil karena serasah dari pohon mangrove tersebut sudah terbawa oleh arus gelombang laut, selai itu kondisi hidrologi seperti pasang surut, presipitasi dan aliran sungai menyebabkan adanya perbedaan yang cukup rumit dibandingkan dengan hutan daratan. Polit dan Brown et al 1996, mengatakan bahwa rendahnya biomassa serasah secara terpisah dapat di jelaskan oelh tingginya laju dekomposisi serasa pada daerah-daerah basah. 
Pendapat lain mengatakan bahwa akumulasi biomassa serasah tidak sepenuhnya merupakan produksi local oleh mangrove tersebut, bahan-bahan organic berupa serasah dan lainnya bisa saja terbawa selama terjadinya psasang tertinggi yang bisa berasal dari sungai ataupun dari lingkungan perairan lainnya yang berdekatan (Boillon dkk dalam Laffoley dan Grimsditch, 2009). Biomassa serasah juga dipengaruhi oleh kerapatan tajuk.Kerapatan tajuk atau tegakan merupakan faktor yang mempengaruhi jatuhnya serasah hutan karena adanya persaingan untuk mendapatkan sinar matahari. Semakin rapat suatu tegakan atau tajuk akan menghasilkan jumlah serasah yang lebih banyak karena pohon-pohon yang tumbuh dalam hutan yang agak rapat lekas melepaskan cabang-cabng dan daun-daun mulai dari bawah, sebab cahaya tidak cukup untuk proses fotosintesis (Rositah dkk,2013). Namun hal ini tidak sepenuhnya berlaku pada lokasi penelitian, dari hasil analisis vegetasi menunjukkan bahwa kerapatan tegakan A.marina jauh lebih besar yaitu $45.88 \%$ jika dibandingkan dengan R.mucronata yaitu $21.18 \%$ namun analisis statistik menunjukkan tidak ada perbedaan diantara kedua jenis tersebut, sehingga dapat dikatakan bahwa kerapatan yang tinggi tidak berbanding lurus denga biomassa lantai hutan karena faktor pasang surut merupakan faktor dominan yang menentukan besarnya biomassa lantai hutan.

Biomassa lantai hutan merupakan bahanbahan organik berupa daun, ranting, cabang, buah, bunga, batang maupun fauna yang jatuh di lantai hutan. Bahan-bahan tersebut apabila terdekomposisi oleh mikroorganisme akan termineralisasi menjadi unsur-unsur yang siap digunakan oleh tanaman (Siarudin dan Rachman, 2008).

Menurut Arif et al, (2003) serasah merupakan bahan organik yang mengalami beberapa tahap proses dekomposisi yang menghasilkan zat yang penting bagi kehidupan dan produktivitas perairan terutama dalam peristiwa rantai makanan. Proses dekomposisi seresah mangrove menghasilkan unsur hara yang diserap kembali oleh tumbuhan dan sebagian larut terbawa oleh air surut ke perairan sekitarnya. Penguraian seresah mangrove di perairan salah satunya di bantu oleh aktivitas mikroorganisme bakteri dan fungi, dalam proses dekomposisi seresah, mikroorganisme mengurai komponen penyusun dinding sel sehingga dihasilkan bahanbahan organik dan unsur hara yang diperlukan pada suatu ekosistem (Imiliyana 2012).Nontji et al (1987) mengatakan bahwa nilai penting dari ekosistem hutan mangrove bukan sebagai sumber daya hutan melainkan juga sebagai penunjang sumber daya perikanan di periaran lepas pantai. Serasah mangrove yang jatuh diuraikan oleh mikroorganisme kemudian masuk ke rantai makanan sehingga dapat menyediakan nutrient bagi organisme yang hidup di perairan sekitarnya.

\subsection{Biomassa Permukaan Total}

Jumlah total keseluruhan biomassa permukaan atas yang ada di hutan mangrove Oebelo disajikan pada Tabel 3.

Tabel 3. Biomassa permukaan total (Mg/ha)

\begin{tabular}{|c|c|c|c|c|c|c|}
\hline \multirow{2}{*}{ Jenis/Parameter } & \multicolumn{2}{|c|}{ Biomassa } & \multicolumn{2}{|c|}{ Stok Karbon } & \multicolumn{2}{|c|}{$\mathrm{CO}_{2}$} \\
\hline & Batang & Serasah & Batang & Serasah & Batang & Serasah \\
\hline Avicennia marina & 118.90 & 0.30 & 54.65 & 0.14 & 200.37 & - \\
\hline Rhizopora mucronata & 28.90 & 0.47 & 13.30 & 0.22 & 48.75 & - \\
\hline Total & 147.70 & 0.77 & 67.94 & 0.36 & 249.21 & - \\
\hline TOTAL & \multicolumn{2}{|c|}{148.47} & \multicolumn{2}{|c|}{68.3} & \multicolumn{2}{|c|}{249.21} \\
\hline
\end{tabular}


Total biomassa mangrove di bagi dengan jumlah plot sebesar $49.49 \mathrm{Mgha}^{-1}$, jika di ekstrapolasi dengan luas hutan mangrove yaitu 1082 ha maka total biomassa sebesar 53548.18 $\mathrm{Mgha}^{-1}$, untuk cadangan karbon sebesar 22.80 $\mathrm{Mg} \mathrm{ha}^{-1}$, jika di ektrapolasi dengan luas hutan maka diperoleh sebesar $24669.60 \mathrm{Mg} \mathrm{ha}^{-1}$, dan untuk serapan karbon sebesar $89881.74 \mathrm{Mg}^{-}$ ${ }^{1}$.Rata-rata stok karbon yang ada di hutan mangrove Oebelo lebih kecil jika dibandingkan dengan cadangan karbon dan $\mathrm{CO}_{2}$ pada pantai Camplong, Sampang-Madura sebesar 196.8549 ton/ha dengan penyerapan $\mathrm{CO}_{2}$ rata-rata sebesar 721.5822 ton/ha untuk tegakan $R$. stylosa (Imiliyana $d k k, 2012$ ) dan penelitian lain yang dilakukan oleh Darmawan dan Siregar, 2008, pada tegakan pohon A. marina di Purwakarta memperoleh hasil stok karbon sebesar 182.5 ton/ha dengan penyerapan $\mathrm{CO}_{2}$ sebesar 669.0 ton/ha.

Hutan mangrove memiliki potensi yang cukup besar dalam menyerap karbon. Hal ini di dasari pada produksi bersih yang dihasilkan mangrove pada tegakan hutan mangrove berumur 20 tahun yaitu biomassa total 62.9398.8 ton/ha/tahun, guguran serasah 5.8-25.8 ton/ha/tahun, riap volume $9 \mathrm{~m} 3 / \mathrm{ha} /$ tahun (Kusmana et al, 2002). Jika dilihat dari hasil perhitungan rata-rata biomassa yang diperoleh yaitu sebesar yaitu $42.97 \mathrm{Mg} \mathrm{ha}{ }^{-1}$, maka biomassa yang dihasilkan ini termasuk rendah.

Menurut Golden Agri-Resources and smart pada tahun 2012 bahwa hutan dengan stok karbon rata-rata 192 ton/ha termasuk hutan dengan kerapatan tinggi, hutan dengan stok karbon 166 ton/ha termasuk hutan dengan kerapatan sedang dan hutan dengan stok karbon 107 ton/ha termasuk dalam hutan dengan kerapatan rendah.(Imiliyana $d k k$, 2012).Jika dilihat dari rata-rata stok karbon yang ada yaitu $22.80 \mathrm{Mg} \mathrm{ha}^{-1}$.maka hutan mangrove di Oebelo termasuk dalam hutan dengan kerapatan rendah. Satoo dan Madgwick et al (1982) mengatakan bahwa biomassa di dalam hutan cenderung bertambah dengan semakin tingginya kerapatan tegakan dan kualitas tapak.Supendi (2007) dalam penelitiannya menunjukkan bahwa semakin tinggi kerapatan maka makin tinggi biomassa. Pada kerapatan pohon 160-170 pohon/ha memiliki biomassa sebesar 301.08 ton/ha dan kerapatan 390-580 pohon/ha memiliki biomassa sebesar 670.75 ton/ha.

Jumlah biomassa dan karbon tersimpan yang berbeda pada setiap kawasan dipengaruhi oleh umur, spesies yang dominan, keadaan ekologis yang ada serta geografis lingkungan setempat (Komiyama $d k k$, 2007).Kondisi iklim (suhu dan curah hujan) juga berpengaruh terhadap kandungan biomassa, suhu dan biomassa yang makin tinggi maka akumulasi biomassa juga makin tinggi (Budi 2000). Soerianegara et al, 1965 telah mengkaji biomassa dari beberapa tegakan hutan yang ada di Indonesia yang berkaitan dengan curah hujan yang hasilnya menunjukkan antara lain biomassa batang berkurang dari $292.6 \mathrm{t} \mathrm{ha}^{-1}$ menjadi $170.158 \mathrm{t} \mathrm{ha}^{-1}$ mengikuti curah hujan tahunan yang menurun dari $3.874 \mathrm{~mm}$ menjadi $1.625 \mathrm{~mm}$ di hutan daratan rendah, Kalimantan Timur. Pada daerah hutan tropis daratan rendah Amazon, biomassa pada daerah dengan rata-rata curah hujan $2700 \mathrm{~mm}$ adalah $356.2 \mathrm{t} \mathrm{ha}^{-1}$ (Nascimento dan Laurance et al, 2002) dan pada daerah dengan curah hujan lebih rendah yaitu $1697 \mathrm{~mm}$ adalah 262. $5 \mathrm{t} \mathrm{ha}^{-1}$ (Fearside, et al 1999).

Karbon tersimpan pada suatu komunitas hutan juga dipengaruhi oleh berat jenis tanaman. Jumlah karbon tersimpan berbeda-beda antara tumbuhan yang satu dengan lainnya, tergantung pada jenis tumbuhan tersebut, karena berbeda jenis berbeda pula berat jenisnya (Pebriandi $d k k, 2013)$. Suatu sistem komunitas hutan yang terdiri dari jenis-jenis pohon yang mempunyai nilai kerapatan kayu tinggi maka biomassanya akan lebih tinggi bila dibandingkan dengan komunitas hutan yang mempunyai jenis-jenis pohon dengan nilai kerapatan kayu rendah (Rahayu $d k k$, 2004). 
Keberadaan mangrove menpunyai dampak yang sangat krusial bagi lingkungan sekitarnya, khusunya dalam penyimpanan karbon. Penelitian yang dilakukan oleh Granek dan Ruttenberg et al 2008, selama delapan tahun menunjukkan adanya pengurangan hingga $50 \%$ karbon tersimpan dalam sediment pada area hutan mangrove yang mengalami pembalakan secara berlebihan. Oleh karena itu pengelolaan, rehabilitasi dan restorasi hutan mangrove tidak hanya memperbesar fungsi ekologis maupun sosio-ekonomi, tapi juga menyediakan tempat penyimpanan $\mathrm{CO}_{2}$ yang efisien baik dalam jangka panjang maupun jangka pendek seperti adanya peningkatan biomassa selama hutan bertumbuh dan peningkatan karbon.

\section{Simpulan dan Saran}

\subsection{Simpulan}

a. Total biomassa pada hutan mangrove Oebelo yaitu Avicennia marina sebesar 118.80 Mg.ha1 dan Rhizopora mucronata sebesar 52.31 Mg.ha- ${ }^{1}$ dengan total keselurahan biomassa sebesar 171.11 Mg.ha- ${ }^{1}$. Hasil uji t menunjukkan adanya perbedaan Avicennia marina dan Rhizopora mucronata.

b. Total stok karbon yang tersimpan pada tegakan Avicennia marina yaitu 54.65 Mg.ha- ${ }^{1} \neg$ dan Rhizopora mucronata sebesar 24.06 Mg.ha-1, total keseluruhan stok karbon yang tersimpan pada saat penelitian sebesar 78.71 Mg.ha- ${ }^{1}$.

c. $\mathrm{CO}_{2}$ yang terserap pada saat penelitian yaitu tegakan Avicennia marina sebesar 200.37 Mg.ha-1 dan tegakan Rhizopora mucronata sebesar 88.23 Mg.ha-1. Total keseluruhan $\mathrm{CO} 2$ yang terserap sebesar 288.60 Mg.ha- ${ }^{1}$.

d. Biomassa nekromassa tidak berkayu secara statistik menunjukkan tidak ada perbedaan diantara ke 2 jenis tegakan. Serasah Rhizopora mucronata menghasilkan biomassa sebesar 0.47 Mg.ha ${ }^{-1}$ dan Avicennia marina sebesar 0.30

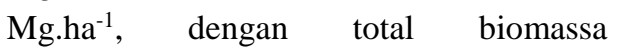
nekromassa tidak berkayu sebesar 0.77 Mg.ha' ${ }^{-1}$.

\subsection{Saran}

a Perlu dilakukan penelitian lanjutan mengenai biomassa bawah agar dapat besarnya kontribusi dari biomassa bawah permukaan terhadap biomassa keseluruhan.

b Perlunya adanya perhatian dari pemerintah agar keberadaannya agar terus berlanjut.

\section{Daftar Pustaka}

Agustin Y L, Muryono M, Purnobasuki H, 2012.Estimasi Stok Karbon Pada Tegakan Pohon Rhizophora Stylosa Di Pantai Talang Iring, PamekasanMadura. Jurusan Biologi, Fakultas Matematika Dan Ilmu Pengetahuan Alam Institut Teknologi Sepuluh Nopember

Ardianto T, 2011. Mangrove Sebagai Penangkap Karbon, Pendingin Udara Serta Penahan Tsunami. http://www.surveypemetaan.blogspot.com. 03 Juni 2013

Budi C, 2000. Model Penduga Biomassa dan Indeks Luas Daun Menggunakan Data Landsat Thematic Mapper (TM) dan Spot Multispektral (XS) di Hutan Mangrove (Studi Kasus Sagara Anakan, Cilacap). Program Pascasarjana.IPB. Bogor

Brown S, 1997. Estimating Biomass and Biomass Change of Tropical Forests.FAO Forestry Paper 134. Diunduh dari http://www.fao.org/docrep/W4095E/ W4095E00.htm tanggal 31-05-2013

Burton V B, Zak D. R, Denton S. R, Spurr S. H, 1998. Forest Ecology. John Wiley \& Sons, Inc 
Daniel C. D., Kauffman J.B., Murdiyarso D., Kurnianto S., Stidham M., Kanninen M. 2011. Mangroves Among The Most Carbon-Rich Forests In The Tropics. Nature Geoscience. DOI: 10.1038.

Dessy L. 2010. Pengaruh Struktur Vegetasi dan Kondisi Lingkungan Fisik Mangrove Terhadap Keanekaragaman Jenis Ikan dan Pendapatan Nelayan di Teluk Kupang. Thesis Ilmu Pengelolaan Sumber Daya Alam. Universitas Nusa Cendana.

Dharmawan I. W. S dan Siregar C.A, 2008. Karbon Tanah dan Pendugaan Karbon Tegakan Avicennia marina (Forsk.) Vierh. Di Ciasem, Purwakarta. Jurnal Penelitian Hutan dan Konservasi Alam Vol. V No. 4 : 317-328, 2008

Dharmawan I. W. S, 2010. Pendugaan Biomassa Karbon Di Atas Tanah Pada Tegakan Rhizophora Mucronata Di Ciasem, Purwakarta. Jurnal Ilmu Pertanian Indonesia, Vol. 15 No. 1, April 2010, Hal 50-56. ISSN 0853-4217

Hairiah K, Rahayu S. 2007. Pengukuran 'Karbon Tersimpan' di Berbagai Macam Penggunaan Lahan. Bogor. World Agroforestry Centre - ICRAF, SEA Regional Office, University of Brawijaya, Unibraw, Indonesia. $77 \mathrm{p}$

Hanafi N., Bernardianto R.B. 2012. Pendugaan Cadangan Karbon Pada Sistem Penggunaan Lahan di Areal PT. Sikatan Wana Raya. Media SainS, Volume 4 Nomor 2.

Imiliyana A. Muryono M, Purnobasuki H. 2012. Estimasi Stok Karbon Pada Tegakan Pohon Rhizophora Stylosadi Pantai Camplong, Sampang-Madura. Jurusan Biologi, Fakultas Matematika Dan Ilmu Pengetahuan Alam Institut Teknologi Sepuluh Nopember

Kathiresan K,Gomathi V, Anburaj R, Saravanakumar K, Asmathunisha N, Sahu S.K, Shanmugaarasu V,
Anandhan S. 2013. Carbon sequestration potential of mangroves and their sediments in southeast coast of India. Faculty of Marine Sciences, Annamalai University, Parangipettai. India

Komiyama A, Ong J. E, Poungparn S, 2007. Allometry, biomass, and productivity of mangrove forests: A review. Aquatic Botany 89 (2008) 128-137

Krisnawati H, Adinugroho W. C, Immanudi R, 2012. Monograf Model-Model Alometrik Untuk Pendugaan Biomassa Pohon pada Berbagai Tipe Ekosistem Hutan di Indonesia. Pusat Peneltian dan Pengembangan Konservasi dan Rehabilitasi. Kementerian Kehutanan

Krisnawati H, Adinuggroho W.C, Imanuddin R, Hutabarat S., 2014. Pendugaan Biomassa Hutan untuk Perhitungan Emisi CO2 di Kalimantan Tengah. Pendekatan komprehensif dalam penentuan faktor emisi karbon hutan. Pusat Penelitian dan Pengembangan Konservasi dan Rehabilitasi, Badan Penelitian dan Pengembangan Kehutanan

MacDicken KG, 1997. A Guide to Monitoring Carbon Storage in Forestry and Agroforestry Projects.Winrock International Development. USA.Institute for Agriculture

Mejupan E, 2001. Pengukuran Biomassa dan Kandungan Hara Kalsium (Ca) di Atas Permukaan Tanah Pada Hutan Rawa Gambut (Studi Kasus di HPH PT. Diamond Raya Timber, Bagan Siapi-Api, Propinsi Dati I Riau). Jurusan Manajemen Hutan Fakultas Kehutanan Institut Pertanian Bogor

Pebriandi, Sribudiani E, Mukhamadun. 2013. Estimation of The Carbon Potential In The Above Ground At The Stand Level Poles And Trees In Sentajo Protected Forest. Departement of Forestry, Faculty of Agriculture, University of Riau 
Rahayu S, Lusiana B Dan Noordwijk Mv, 2004. Pendugaan Cadangan Karbon Di Atas Permukaan Tanah Pada Berbagai Sistem Penggunaan Lahan Di Kabupaten Nunukan, Kalimantan Timur. World Agroforestry Centre, Cida, Care

Siarudin M, Rachman E, 2008.. Biomassa Lantai Hutan Dan Jatuhan Serasah Di Kawasan Mangrove Blanakan, Subang, Jawa Barat. Balai Penelitian Kehutanan Ciamis

Simon H, 2007. Metode Inventore Hutan. Pustaka Pelajar. Yogyakarta

Standar Nasional Indonesia (SNI), 2011. Pengukuran dan Penghitungan Cadangan Karbon-Pengukuran Lapangan Untuk Penaksiran Cadangan Karbon Hutan (Ground Based Forest Carbon Accounting). SNI 7724

Sumiyati S, 2010. Hubungan Antara Struktur Komunitas Vegetasi Mangrove dengan Keanekaragaman Ekologis dan tensi Ekonomis Gastropoda dan Bivalvia di Perairan Pesisir Oebelo dan Tanah Merah Kabupaten Kupang. Thesis. Ilmu Pengelolaan Sumber Daya Alam, Pascasarjana Undana
Supendi D.P. 2007. Penduga Biomassa Tegakan Pinus (Pinus merkusii Jungh et de Vriese) Pada Berbagai Kerapatan di Hutan Pendidikan Gunung Walat Sukabumi. Program Studi Budidaya Hutan Fakultas Kehutanan Institut Pertanian Bogor

Tua M, 2011. Hubungan Antara Kepadatan Komunitas Mangrove dengan Keragaman Meroplankton di Perairan Pesisir Oebelo dan Tanah Merah Kabupaten Kupang. Thesis. Ilmu Pengelolaan Sumber Daya Alam, Pascasarjana Undana

Yuniawati, Budiaman A, Elias. 2011. Estimasi Potensi Biomassa dan Massa Karbon Hutan Tanaman di Lahan Gambut (Studi Kasus di Areal HTI Kayu Serat di Pelalawan, Propinsi Riau). Jurnal Penelitian Hasil Hutan Vol. 29 No. 4, Desember 2011: 343-355

Zacharias A. B, 2005. Dampak Penerapan Teknologi Pengelolaan Garam Terhadap Peningkatan Kesejatraan Masyarakat dan Pelestarian Sumber Daya Alam di Kawasan Teluk Kupang (Studi Kasus Kabupaten Kupang). Thesis. Ilmu Pengelolaan Sumber Daya Alam, Pascasarjana Undana 